\title{
Association of severity of coronary artery disease by SYNTAX score (SS) and lower extremity arterial disease by duplex ultrasound (DUS) study—an Indian perspective
}

Saumen Nandi ${ }^{1}$, Anindya Mukherjee ${ }^{1^{*}}$ (D), Dibbendhu Khanra ${ }^{2}$ and Kaushik Biswas ${ }^{1}$

\section{Abstract}

Background: Coronary artery disease (CAD) and lower extremity artery disease $\mathrm{EAD}$ ) often coexist. Ankle brachial index (ABI) has been shown to be an independent predictor of CAD. LEAD on the basis of $A B I$ and also invasive angiography. But rigorous sparching did not reveal any similar research where severity of LEAD was assessed by duplex ultrasound (DUS). In this study, we assessed the association of severity and /Calis on of LEAD by DUS with SYNTAX score (SS).

Results: A total of 637 subjects above 45 years of age with ron ry angiographic confirmation of CAD were studied in this single centre cross-sectional, descriptive and ar tical research. High SS was significantly more common in subjects with LEAD ( $p=0.04)$. In the significantly more proportion of subjects with high S. Dhogressive increase in mean SS was noted across the grades of arterial disease in the femoro-ps oli segment ( $p=0.007)$. 85.2\% of the LEAD was in the femoropopliteal segment, while below-knee art rial dis o swas present in 98.5\% of subjects with LEAD. Hypertension, smoking, history of CVE and present tion with ACS independently increased the risk of LEAD.

Conclusion: High prevalence of asy tomat C LEAD and association of high SS with LEAD as a whole as well as femoro-popliteal involvement suggests need for a point of care DUS study (POCUS) since treatment varies with location and extent of disease CAD and LEAD from Indian sub-Ontinent till date and also the first study to use non-invasive tool as DUS for LEAD assessment while sty yyin its as ociation with CAD makes this a landmark experience.

\section{Background}

Approximately 40, vatients have coexisting coronary artery di ease (CAD) and lower extremity artery disease (LEAD) bot share the similar risk factors. When on scula ogion is diseased, there has been a trend in inic nractice, to look for lesions in various vascular as $[1,2]$. Moreover, coexistence of peripheral arterial

* Correspondence: anindya768@yahoo.co.in

${ }^{1}$ Department of Cardiology, NRS Medical College, Kolkata, India

Full list of author information is available at the end of the article disease (PAD) in a patient of CAD increases the risk of mortality [3-6]. LEAD increases with age with a prevalence of $10-25 \%$ in the general population aged $>55$ years [7]. Ankle brachial index (ABI) has been shown to be an independent predictor of CAD in several studies [8]. The guidelines recommend duplex ultrasound (DUS) as the first-line imaging for LEAD lesions in combination with $\mathrm{ABI}$ measurement due to its high sensitivity, specificity and higher effectiveness at a lower cost per quality-adjusted life-year (QALY) compared to other 
imaging techniques $[9,10]$. SYNTAX score (SS) for coronary angiography has become popular as it can guide the appropriate treatment protocol for revascularization and provides prognostic information [11]. Multiple studies have reported association or correlation of CAD and PAD on the basis of $A B I$ and also invasive peripheral angiography [12-15]. But rigorous searching did not reveal any research studying the association of CAD and LEAD where severity of PAD was assessed by DUS.

In this study, our objectives were to assess the association of severity of CAD and LEAD by SS and DUS respectively and to find any relation of localisation of LEAD by DUS and severity of CAD by SS.

\section{Methods}

\section{Subjects}

This research was conducted as a single centre crosssectional, descriptive and analytical study. Subjects who were admitted to the cardiology department of a tertiary care centre of Eastern India were recruited consecutively over a period of 15 months from 1 May 2018 to 31 July 2019. Purposive sample size was calculated to be $\geq 385$ to have confidence level of $95 \%$ that the real values are within $\pm 5 \%$ of measured or surveyed value [https://www. calculator.net/sample-size-calculator.html]. Patients a jove 45 years of age with coronary angiographic confir tic of CAD were included. Exclusion criteria were creati clearance $\leq 30 \mathrm{~mL} / \mathrm{min}$, previous surgery or srventio, for LEAD, history of percutaneous coromery int ention (PCI) or coronary artery bypass grafing (CABG), past trauma, surgery in last 3 months, a v malighancy, any other inflammatory condition and an ti-irflammatory drug intake apart from aspirin 11 procedures followed were in accordance with the etlica ndards of the responsible committee on nan experimentation (institutional and national) w the Helsinki Declaration of 1964 and later ressions nformed consent was obtained from all patient $s$ being cluded in the study.

\section{Clinical irdices}

Detailea stury i cluding age, smoking history, diabetes, hyr ensio chronic kidney disease (CKD), cerebrovaslar vents ,CVE), and claudication was taken. Claudica n was defined as a pain, cramp or sense of fatigue in a scle group of the lower limbs related to sustained exercise and relieved with a few minutes of rest while standing evenly on both feet [16]. It was assessed by the Edinburgh claudication questionnaire [17]. Medicine history was documented. Detailed physical examination including height, weight, body mass index (BMI) and cardiovascular system examination was carried out. These were recorded in a proforma sheet. Smokers included both current and past smokers. Hypertension was defined as systolic blood pressure $>140 \mathrm{~mm} \mathrm{Hg}$ and/or diastolic blood pressure $>90 \mathrm{~mm} \mathrm{Hg}$ or if the patient was on antihypertensive medications.

\section{Laboratory parameters}

Lipid parameters and blood glucose were tested apart from routine pre angiographic investigations hich included transthoracic echocardiography and c inine clearance. Dyslipidaemia was diagnosed as per d Association of India Expert Consensu. Statem nt on Management of Dyslipidaemia in Mutians when the subject was on lipid-lowering $\mathrm{m}$ dicines [18]. Subjects having fasting blood glucose ( $\mathrm{l}$ G) $>26 \mathrm{mg} / \mathrm{dL}$ or patients on anti-diabetic mo ines diagnosed as diabetes mellitus. Tran thorach chocardiography was done by Vivid S5 pac e with a M3S matrix array probe with a frequency ran from 1.7 to $3.2 \mathrm{MHz}$ (GE Vingmed, Horten, Jorway), and basic 2-dimensional and $\mathrm{M}$-mode $\mathrm{n}$ its were done with evaluation of left ventricular ection fraction (LVEF). Each echocardiogra tudy was associated with machine integrated ECCYeco, ding.

\section{Du.}

DUS as performed before doing coronary angiography a After the subject had rested for at least $5 \mathrm{~min}$ in supine position. It was carried out by three experienced radiologists who were blinded to clinical data and consensus was required between at least two of them. PHIL IPS iu22 xMATRIX Ultrasound system using $1-3 \mathrm{MHz}$ Broadband linear array transducer and $5-7 \mathrm{MHz}$ curved array transducer with colour Doppler and power Doppler assessment was used. The wall, lumen and flow of the common femoral artery (CFA), superficial femoral artery (SFA), popliteal artery (PA), anterior tibial artery (ATA) and posterior tibial artery (PTA) were evaluated. Velocity criteria were based on the peak systolic velocity (PSV) and velocity ratio (VR). LEAD was classified into mild (1-49\% stenosis), significant (50-99\% stenosis) and total occlusion (100\% stenosis) [19].

\section{CAD and SS}

Three experienced interventional cardiologists, who were blinded to clinical data, analysed the coronary angiogram performed using conventional techniques by radial artery access. Consensus was required between at least two of them. The lesions were described on the basis of location, number, extent of involvement, thrombus burden, extent of calcification, tortuosity of involved segments, bifurcation or trifurcation involvement and total occlusion. Scoring was done for each lesion. The SYNTAX Score Calculator software version 2.11 (SYNTAX Score Working Group, www.syntaxscore. com) was used to deduce the SS [11]. The SS was graded 
into low (0-22), intermediate (23-32) and high (> 32) risk.

\section{Statistical analysis}

SPSS version 25.0 (IBM Co, Armonk, NY, USA) was used for data analysis. The continuous variables were presented as the mean \pm standard deviation (SD) or median with range, and the categorical variables were presented as percentages. Mann-Whitney test or independent $t$ test was used to compare continuous variables among groups and the chi-square test for comparison of proportional data. Chi-square test was used to evaluate categorical parameters and estimation of risk. Analysis of correlations between categorical variables and risk factors was done by binary logistic regression analysis, and continuous variables were analysed by multivariate linear regression analysis. All statistical tests were twotailed, and $p<0.05$ was considered significant.

\section{Results}

\section{Patient's baseline characteristics}

A total of 637 subjects above 45 years of age with coronary angiographic confirmation of CAD were studied.
Patients' baseline characteristics and comparison of characteristics among subjects with and without LEAD is shown in Table 1. Two hundred three subjects (31.9\%) had LEAD while it was absent in $68.1 \%$. $85.7 \%$ of the subjects with LEAD were male $(p=0.008)$. Hypertension $(77.3 \%)$ and smoking (61.1\%) were significantly more prevalent among subjects with LEAD. CVE oc urred in significantly more number of subjects having LE $(p=$ 0.003). 76.4\% of patients with LEAD complained or dication while the rest were asymptoma. $56.4 \%$ or the study population had acute coron ary syn $\mathrm{m} /$ (ACS) while the rest had stable ischemi heart dises.se (SIHD). ACS patients comprised $64.5 \%$ of bjects with LEAD ( $p$ $=0.005)$. Overall mean age, an and LVEF were $61.8 \pm 8.4$ years, $25.2 \pm 2.5 \mathrm{k}_{\mathrm{z}} \eta^{2}$ and $44.9 \pm 7.3 \%$ respectively with no sig cicant difference between the two groups. $45.1 \%$ of all su cts were diabetic, with no significant differen of presence of diabetes between the groups. $\mathbb{N}$ of the subjects were having hypercholesterole with no significant difference between sub with and without LEAD.

Baseline vapyatelet, statin and antidiabetic medication intake was ignificantly less among subjects with LEAD.

Table 1 Patients' baseline characteristics and comparison of charo

ristics mong subjects with and without LEAD

\begin{tabular}{|c|c|c|c|c|c|}
\hline & $\begin{array}{l}\text { LEAD present } \\
n=203(\%)\end{array}$ & $\begin{array}{l}\text { LEAD abse } \pi \\
n=434\end{array}$ & $\begin{array}{l}\text { Torial } \\
n=637(\%)\end{array}$ & Difference/OR (95\% Cl) & $p$ value \\
\hline Age in years & $61.4 \pm 7.9$ & & $61.8 \pm 8.4$ & $-0.7(-2.1-0.7)$ & 0.3 \\
\hline Male gender & $174(85.7)$ & & $506(79.4)$ & $1.8(1.2-2.9)$ & $0.008^{*}$ \\
\hline BMI & $24.9 \pm 2.3$ & & $25.2 \pm 2.5$ & $-0.4(-0.8-0.02)$ & 0.06 \\
\hline Diabetic & $97(47.8)$ & $190(43.8)$ & $287(45.1)$ & $1.2(0.8-1.6)$ & 0.35 \\
\hline Hypertensive & $157(77.3)$ & $29)(68.0)$ & $452(71.0)$ & $1.6(1.1-2.36)$ & $0.01^{*}$ \\
\hline Hypercholesterolemia & $(9)^{-1}$ & $419(96.5)$ & $616(96.7)$ & $1.2(0.5-3.1)$ & 0.82 \\
\hline Smoker & & $217(50.0)$ & $341(53.5)$ & $1.6(1.1-2.2)$ & $0.01^{*}$ \\
\hline CKD & & $51(11.8)$ & $61(9.6)$ & $0.4(0.2-0.8)$ & $0.006^{*}$ \\
\hline CVE & & $4(0.9)$ & $14(2.2)$ & $5.6(1.7-17.9)$ & $0.003^{*}$ \\
\hline Claudication & & $6(1.4)$ & $161(25.3)$ & $\begin{array}{l}230.4(96.7-548.9) \\
\operatorname{Ln} 5.4(4.6-6.3)\end{array}$ & $<0.0001^{*}$ \\
\hline ACS & $31(64.5)$ & $228(52.5)$ & $359(56.4)$ & $0.6(0.4-0.8)$ & $0.005^{*}$ \\
\hline EF (\%) & $44.3 \pm 8.1$ & $45.2 \pm 6.8$ & $44.9 \pm 7.3$ & $0.9(-2.1-0.3)$ & 0.1 \\
\hline & $167(82.3)$ & $393(90.5)$ & $568(89.2)$ & $8.2(2.2-15.2)$ & $0.006^{*}$ \\
\hline & $156(76.8)$ & $401(92.4)$ & $557(87.4)$ & $15.6(8.94-23.2)$ & $<0.0001^{*}$ \\
\hline & $111(54.7)$ & $215(49.5)$ & $326(51.2)$ & $5.2(-6.2-16.3)$ & 0.4 \\
\hline Beta-b, kers & $99(48.8)$ & $216(49.8)$ & $315(49.5)$ & $1.0(-10.7-12.67)$ & 0.9 \\
\hline $\mathrm{CCB}$ & $34(16.7)$ & $74(17.1)$ & $108(17.0)$ & $0.4(-16.8-13.9)$ & 0.9 \\
\hline Nitrates & $165(81.2)$ & $366(84.3)$ & $531(83.3)$ & $3.1(-3.5-10.6)$ & 0.4 \\
\hline Antidiabetics & $77 / 97(79.4)$ & 180/ 190 (94.7) & $257 / 287$ (89.5) & $15.3(6.6-25.9)$ & $0.0002^{*}$ \\
\hline SS & $23.2 \pm 9.5$ & $21.7 \pm 8.6$ & $22.2 \pm 8.9$ & $1.5(-0.03-3.0)$ & 0.06 \\
\hline
\end{tabular}

Data given as mean \pm SD or $n(\%)$

$A C E I / A R B$ angiotensin-converting enzyme inhibitor/angiotensin receptor blocker, $A C S$ acute coronary syndrome, $B M I$ body mass index, $C C B$ calcium channel blockers, $C l$ confidence interval, $C K D$ chronic kidney disease, $C V E$ cerebrovascular event, $E F$ ejection fraction, $L E A D$ lower extremity arterial disease, $O R$ odds ratio, SD standard deviation, SS SYNTAX score, * significant 
There was no difference between the groups in usage of angiotensin-converting enzyme inhibitor/angiotensin receptor blocker (ACEI/ARB), beta-blockers, calcium channel blockers $(\mathrm{CCB})$ and nitrates.

\section{LEAD and SS}

High SS was significantly more common in subjects with LEAD $(p=0.04)$ (Fig. 1a).

In the femoro-popliteal segment, total occlusion of arteries were found in significantly more proportion of subjects with high SS (9.3\%) than low and intermediate SS separately. Significant occlusion in the femoropopliteal segment was also more prevalent in the subjects with high SS whereas in the below-knee arterial segment no such association was noted $(p=0.08)$. Mean SS was $22.2 \pm 8.9$ with no significant difference between the two groups (Table 1). A progressive increase in mean SS was noted across the grades of arterial disease in the femoro-popliteal segment $(p=0.007)$. Though mean SS was more in subjects with significant occlusion and total occlusion in the below-knee arterial segment than those with normal arteries, no significant association was noted in this segment between mean $\mathrm{SS}$ and grades of LEAD $(p=0.06)$.

\section{Distribution of LEAD}

Figure $1 \mathrm{~b}$ shows the distribution of odstru an/n subjects with LEAD. Figure 2a shows he overall sistribution of LEAD. Above $80 \%$ of the LEA were in below-knee arteries (ATA and PTA) wh as $10-20 \%$ of the disease were in the CF . Figu $\mathrm{b}$, shows the median distribution and rarge $f$ SS across the severity of femoro-popliteal and below ree disease.

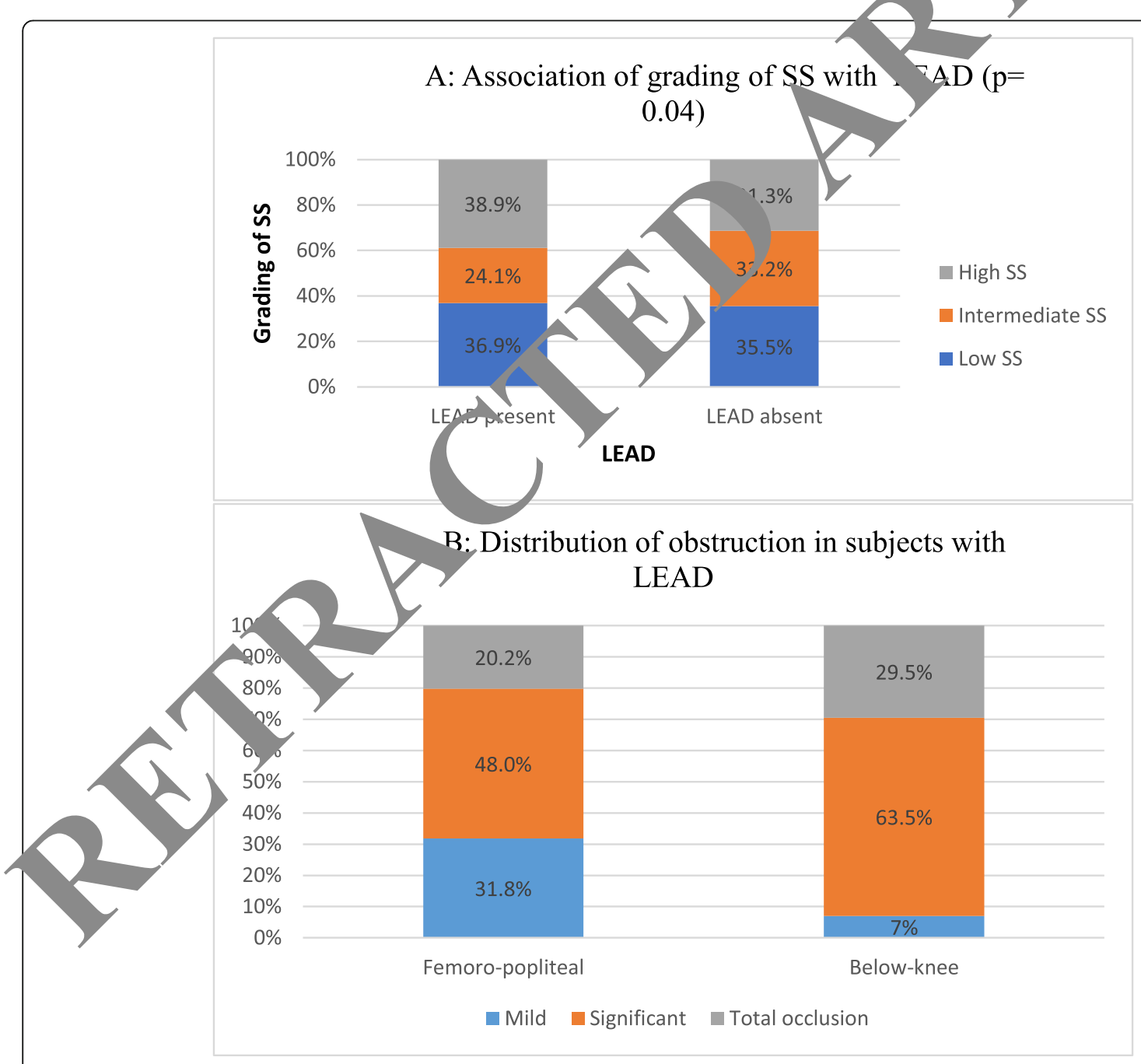

LEAD= lower extremity arterial disease; SS= syntax score

Fig. 1 a Association of grading of SS with LEAD $(p=0.04)$. b Distribution of obstruction in subjects with LEAD. LEAD, lower extremity arterial disease; SS, SYNTAX score 


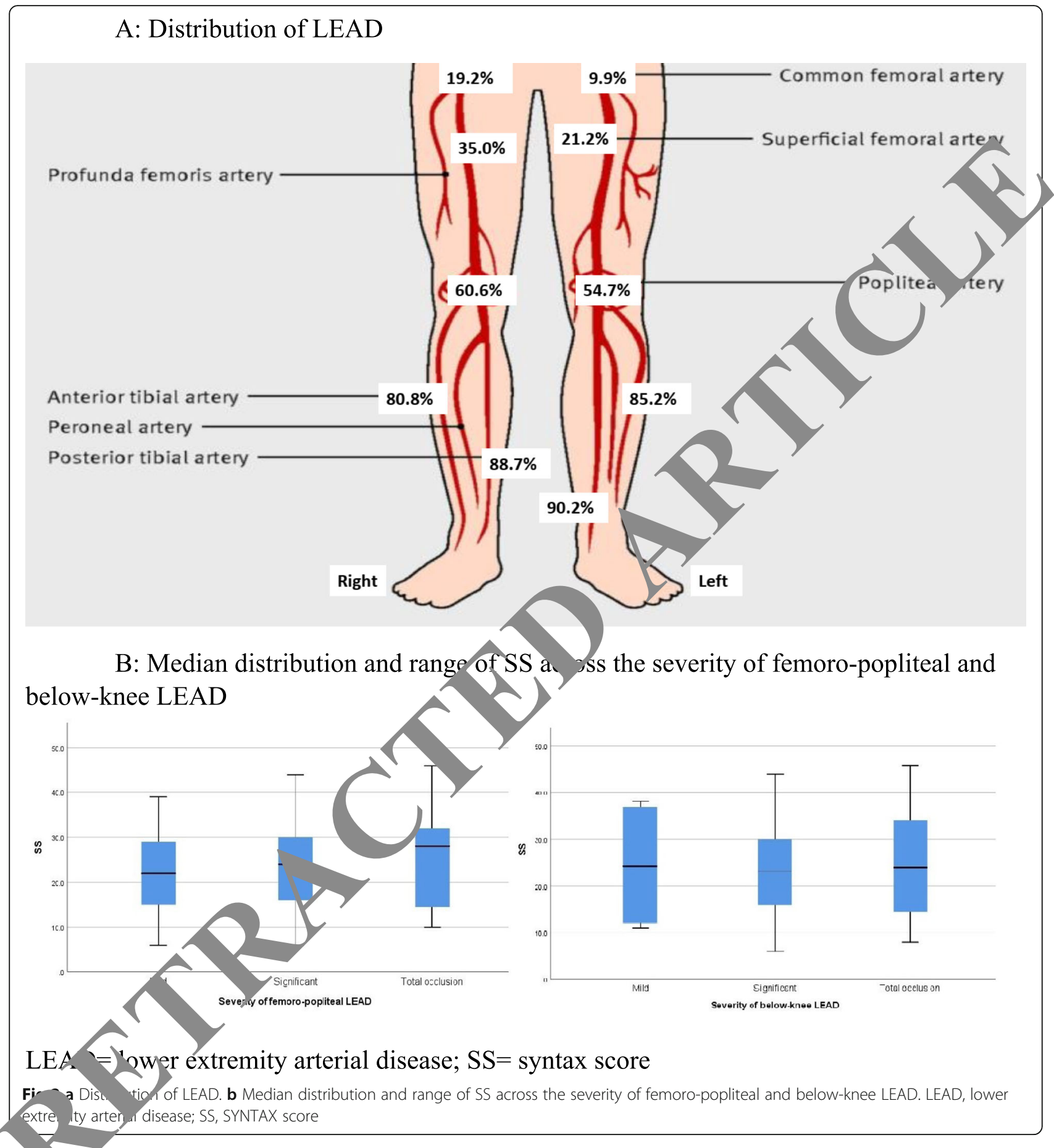

Ta. segmental distribution into account, $85.2 \%$ of the LEAD was in the femoro-popliteal segment, while below-knee arterial disease was present in $98.5 \%$ of subjects with LEAD (95\% CI 8.2-18.9, $p<0.0001)$.

\section{Multinomial logistic regression}

Table 2 shows multinomial logistic regression for detection of independent contribution of the baseline factors in LEAD. Keeping other baseline parameters fixed, hypertension, smoking, history of CVE and presentation with ACS independently increased the risk of LEAD. Presence of CKD was found to have independent negative association with LEAD.

\section{Discussion}

Atherosclerosis affects various arterial territories simultaneously since it is a systemic pathological process. Thus, a person with atherosclerotic disease in one vascular 
Table 2 Predictors of LEAD in patients with CAD

\begin{tabular}{lllllll}
\hline Variables & \multicolumn{1}{l}{ Univariate } & & \multicolumn{1}{l}{ Multivariate } & \\
\cline { 2 - 3 } \cline { 6 - 7 } \cline { 6 - 7 } Male gender & $1.8(1.2-2.9)$ & 0.008 & & $1.5(0.9-2.5)$ & 0.1 \\
Hypertension & $1.6(1.1-2.36)$ & 0.01 & & $1.9(1.3-2.9)$ & $0.002^{*}$ \\
Smoker & $1.6(1.1-2.2)$ & 0.01 & & $1.5(1.01-2.2)$ & $0.046^{*}$ \\
CKD & $0.4(0.2-0.8)$ & 0.006 & & $0.4(0.2-0.8)$ & $0.01^{*}$ \\
CVE & $5.6(1.7-17.9)$ & 0.003 & & $3.8(7.3-12.7)$ & $0.03^{*}$ \\
ACS & $0.6(0.4-0.8)$ & 0.005 & & $0.7(0.5-0.97)$ & $0.03^{*}$ \\
\hline
\end{tabular}

We adjusted the result for male gender, hypertension, smoker, CKD, CVE and ACS

$A C S$ acute coronary syndrome, $C A D$ coronary artery disease, $C l$ confidence interval, CKD chronic kidney disease, CVE cerebrovascular event, LEAD lower extremity arterial disease, $O R$ odd ratio, * significant

territory has higher risk of disease in other territories as well [20-22].

\section{Prevalence of LEAD in subjects with CAD}

LEAD is prevalent in $7-16 \%$ of subjects with CAD as per the Western data [9]. An Indian study by Saran et al. reported the prevalence to be $7.7 \%$, but this was based on only ABI measurement [23]. We found the prevalence of LEAD in subjects with CAD to be $31.9 \%$ which was much higher than this previous study by Saran et ail. but corroborated with the Indian data by Sarangi $c r$ ar. (33.3\%) [12]. We attribute this higher prevalence th ? use of better diagnostic modality in form of Dy. His sample size in our study $(n=637)$ than a study b) Saran et al. $(n=207)$ may have also providea better picture.

\section{Baseline characteristics}

A study has documented the aciation of complexity in peripheral arterial lesions $\mathrm{vl}_{\mathrm{i}}$ omplex coronary lesions while another sho wed the increased risk for adverse cardiova lar mants in patients with LEAD $[24,25]$. Baseline 11sk ta ors like age, gender, hypertension, diabetes a dyslips, aemia should be taken into account while ana, ing such associations. In the study by Petrace et al., the baseline demographics were similar we groups whereas Sarangi et al. rep ed $\mathrm{t}$ odedominance of PAD in diabetics and nok is [12, 15]. Falcão et al. found a significantly h. rr number of female subjects and subjects with ACS in th PAD group while Saran et al. reported significantly higher mean age, prevalence of diabetes and hypertension in subjects with $\mathrm{ABI}<0.9[14,23]$. In our study, male gender, hypertension, smoking, CVE and ACS were significantly more prevalent in the LEAD group. Baseline intake of antiplatelet, statin and antidiabetic medications were significantly less in subjects with LEAD which may have contributed to the progression of atherosclerotic disease process.
United States Preventive Services Task Force (USPSTF) states that the benefit of screening for PAD and CAD risk in asymptomatic adults with ABI is not clear cut with current evidence [26]. In our study, 23.6\% subjects with DUS diagnosed LEAD were asymptomatic which is quite a sizeable proportion and thus further research reg rding benefit of screening and the screening tool to b used is warranted.

\section{LEAD and SS}

The study by Korkmaz et al. on 150 patie with ACS reported higher $\mathrm{SS}$ in subjects wit $\mathrm{ABI} \leq 0.9, p<0.001)$ [27]. Benyakorn et al. included a 1 re proportion of subjects with valvular heart dis a ar also demonstrated significant negat se corr ion between ABI and SS [28]. Falcão et al. fou that correlation between ABI and SS was lost when anal, was done among patients of obstructive CA $(p=0.148)$ [14]. Petracco et al. reported negat con between ABI and SS but it was statistically in nificant [15]. In our study, high SS $(>32)$ was frequently noted in subjects with LEAD $(p=0.04)$ bat, nean SS did not vary significantly between the tiro groups.

\section{Tistri tition of LEAD}

1 ro-popliteal disease was more common than other discributions according to studies by Diehm et al. (51.2\%), Hatmayer et al. (77\%), Vogt et al. (47.3\%) and Chen et al. (common femoral 57.6\%) [29]. Contrary to the above data, our study revealed significantly more below-knee arterial disease than femoro-popliteal disease $(p<0.0001)$. This discrepancy may be attributed to the difference of baseline characteristics of the subjects.

Vuruskan et al. found that angiographic critical stenosis in femoro-popliteal segment was most reliable for the determination of subjects with high SS [30]. In the present study, significant and total occlusion of the femoro-popliteal segment arteries by DUS were found in significantly more proportion of subjects with high SS $(p=0.02)$. No such association was noted in the below-knee arterial segment $(p=0.08)$.

\section{Predictors of peripheral artery disease in patients with CAD}

Saleh et al. found independent association of age, hypertension, diabetes mellitus and smoking with PAD [31]. Another study found PAD was independent risk factor for CAD and CVE [13]. In the present study, hypertension, smoking, history of CVE and presentation with ACS independently increased the risk of LEAD. Strikingly, the presence of CKD was found to have independent negative association with LEAD which can be due to platelet and clotting factor dysfunction in CKD but needs further insight. 


\section{Limitations}

The sample size was sizeable but larger population would give a better picture. This study does not provide outcome data due to lack of follow-up. Hospitalised patients with coronary angiographic confirmation of CAD were included thus automatically selecting a population with higher possibility of LEAD. Thus, these results should be treated with caution in general population. We studied only anatomical presentation of coronary and LEAD by angiographic calculation of SS and DUS respectively. Functional assessment of the lesions might find a more robust relationship between the diseases in two territories. Lower limb angiography was not performed hence extent and burden of underlying atherosclerosis may have not been accurately reflected. Exclusion of assessment of renal and aorto-iliac segments also remains a limitation. Randomised studies specifically designed for this purpose are needed to affirm the findings.

\section{Conclusion}

High prevalence of asymptomatic LEAD and association of high SS with LEAD as a whole as well as femoropopliteal involvement suggests the need for a point of care DUS study (POCUS) which is being already used in multiple fields, since treatment varies with location and extent of disease which cannot be appreciated by ADI alone.

\section{Abbreviations}

ABI: Ankle brachial index; ACS: Acute coronary syndrome; artery; BMl: Body mass index; CABG: Coronary artery byp-ss lgraft CAD: Coronary artery disease. CFA. Common femora artery: CKD: Ch CAD: Coronary artery disease; CFA: Common femora artery; CKD: Ch,
kidney disease; CVE: Cerebrovascular events; DUS: uplex ultrasound; FBG: Fasting blood glucose; LEAD: Lower extremit, tery disea se: PA: Popliteal artery; PAD: Peripheral arterial disease; Derci aneous intervention; PSV: Peak systolic velocity; P - Rosterior unid artery; SD: Standard deviation; SFA: Superficial fem heart disease; SS: SYNTAX score; USPSTF: Un te Sta es Preventive Services Task Force; VR: Velocity ratio

\section{Acknowledgements}

None

\section{Authors' contribu ions}

AM and DK mack substantic Thtributions to the conception and design of the work; $C$ AM and KB to the acquisition, analysis and interpretation of data; AM a 7 , mine rafted the work and substantively revised it, SN, AM, DK and KB ha opro ved the submitted version and have agreed both to b. per lally aco ntable for the author's own contributions and to ensure qu nererated to the accuracy or integrity of any part of the work, ev nes mir which the author was not personally involved, are appro, toly investigated, resolved, and the resolution documented in the literatude.

\section{Funding}

None

\section{Availability of data and materials}

The datasets used and/or analysed during the current study are available from the corresponding author on reasonable request.
Institutional ethics committee of NRS Medical College, Kolkata, India, approved the study. Reference no. - No/NMC/959.

Informed written consent for participation was obtained from individual patients.

\section{Consent for publication}

N/A as anonymity was not compromised.

\section{Competing interests}

The authors declare that they have no competing interests.

\section{Author details}

${ }^{1}$ Department of Cardiology, NRS Medical College, Kolkata, via. ${ }^{2} \mathrm{He} \mathrm{t}$ and Lung Centre, New Cross Hospital, Royal Wolver

Town, Wolverhampton, UK.

Received: 10 July 2020 Accepted: 27 gus

Published online: 07 September 20

\section{References}

1. Pellegrino T, Storto G, Fila di PP (2005) Relationship betweenbrachial artery flow-mediated tation and lary flow reserve in patients with peripheral artery aiseas Nucl Med 46(12):1997-2002

2. Ross AJ, Gao 2 , $k$ (2017) Coronary exercise hyperemia is impaired in paties with peripheral arterial disease. Ann Vasc Surg 38: 260-267

3. Eagle KA Foster ED, Mickel MC, Gersh BJ (1994) Long-termsurvival in patient. wit disease. Th coronary artery surgery study (CASS)investigators. J Am collCardiol $2 \% 1091-1095$

4. nholz HM, Chen J, Chen YT, Wang Y, Radford MJ (2001) Predicting oneye mortality among elderly survivors of hospitalization for anacute cardial infarction: results from the cooperative cardiovascular project. J CollCardiol 38:453-459

Chiu JH, Topol EJ, Whitlow PL, Hsu AP, Tuzcu EM, Franco I, Moliterno DJ (2003) Peripheral vascular disease and one-year mortality following percutaneous coronary revascularization. Am J Cardiol 92:582-583

6. Narins CR, Zareba W, Moss AJ, Marder VJ, Ridker PM, Krone RJ, Lichstein E (2004) Relationship between intermittent claudication, inflammation, thrombosis, and recurrent cardiac events among survivors ofmyocardial infarction. Arch Intern Med 164:440-446

7. Cimminiello C (2002) Peripheral arterial disease - epidemiology and pathophysiology. Thromb Res 106:295-301

8. Leng GC, Fowkes FGR, Lee AJ (1996) Use of the ankle brachial pressure index to predict cardiovascular events and death - a cohort study. BMJ 313: 1440-1444

9. Aboyans V, Ricco JB, Bartelink MEL, Björck M, Brodmann M, Cohnert T, Collet JP, Czerny M, De Carlo M, Debus S, Espinola-Klein C, Kahan T, Kownator S, Mazzolai L, Naylor AR, Roffi M, Röther J, Sprynger M, Tendera M, Tepe G, Venermo M, Vlachopoulos C, Desormais I, ESC Scientific Document Group (2018) 2017 ESC guidelines on the diagnosis and treatment of peripheral arterial diseases, in collaboration with the European Society for Vascular Surgery (ESVS): document covering atherosclerotic disease of extracranial carotid and vertebral, mesenteric, renal, upper and lower extremity arteries endorsed by: the European stroke organization (ESO) the Task Force for the diagnosis and treatment of peripheral arterial diseases of the European Society of Cardiology (ESC) and of the European Society for Vascular Surgery (ESVS). Eur Heart J 39(9):763-816

10. Collins R, Cranny G, Burch J, Aguiar-Ibanez R, Craig D, Wright K, Berry E, Gough M, Kleijnen J, Westwood M (2007) A systematic review of duplex ultrasound, magnetic resonance angiography and computed tomography angiography for the diagnosis and assessment of symptomatic, lower limb peripheral arterial disease. Health Technol Assess 11:1-184

11. Serruys PW, Morice M-C, Kappetein AP et al (2009) Percutaneous coronary intervention versus coronary-artery bypass grafting for severe coronary artery disease. New Engl J Med 360(10):961-972

12. Sarangi S, Srikant B, Rao DV, Joshi L, Usha G (2012) Correlation between peripheral arterial disease and coronary artery disease using ankle brachial index-a study in Indian population. Indian Heart J 64(1):2-6

13. Pang $X H$, Han J, Ye WL, Sun $X$, Ding $Y$, Huang WJ, Zhao YM, Lou HY, Shan LZ, Kang YX, Song XX, Zhang SZ, Gu W, Shan PF (2017) Lower extremity 
peripheral arterial disease is an independent predictor of coronary heart disease and stroke risks in patients with type 2 diabetes mellitus in China. Int J Endocrinol 2017:9620513

14. Falcão FJ, Rodrigues Alves $C M$, Caixeta $A$, de FreitasGuimarães $L$, de Sousa Filho JT, Soares JA, Helber I, Carvalho AC (2013) Relation between the anklebrachial index and the complexity of coronary artery disease in older patients. ClinInterv Aging 8:1611-1616

15. Petracco AM, Carlos BL, Farias PG, Santos TG, de Oliveira PD, Claudio DL et al (2018) Assessment of the relationship of ankle-brachial index with coronary artery disease severity. Int J Cardiovasc Sci 31(1):47-55

16. Smith RB III (1990) Claudication. In: Walker HK, Hall WD, Hurst JW, (ed) Clinical methods: the history, physical, and laboratory examinations, 3rd edn. Boston: Butterworths; Chapter 13. Available from: https://www.ncbi. nlm.nih.gov/books/NBK235/

17. Edinburgh claudication questionnaire. (2002). Occasional paper (Royal College of General Practitioners), (82), 44.

18. lyengar SS, Puri R, Narasingan SN (2016) Lipid Association of India Expert Consensus Statement on Management of Dyslipidemia in Indians 2016: part 1 - executive summary. J Clin Prev Cardiol 5:51-61

19. Eiberg JP, Grønvall Rasmussen JB, Hansen MA, Schroeder TV (2010) Duplex ultrasound scanning of peripheral arterial disease of the lower limb. Eur J Vasc Endovasc Surg 40:507-512

20. Heras M, Chamorro A (2000) Atherosclerosis: a systemic condition that requires a global approach. Eur Heart J 21(11):872-873

21. Viles-Gonzalez JF, Fuster V, Badimon JJ (2004) Atherothrombosis: a widespread disease with unpredictable and life-threatening consequences. Eur Heart J 25(14):1197-1207

22. Saçar M, Önem G, Sarıoğlu Büke A et al (2013) The effect of distance based learning on the fifth stage medical students' perception in peripheral vascular diseases course: a questionnaire survey. Anadolu Kardiyol Derg 13(3):275-277

23. Saran $R$, Bhagat $R$, Narain $V$ et al (2012) Prevalence of peripheral arterial diseases in patient with coronary artery diseases of Indian origin. Heart 98:E266

24. Aykan AÇ, Hatem E, Karabay CY et al (2015) Complexity of lower ext amit peripheral artery disease reflects the complexity of coronary artery Vascular. 23(4):366-373

25. Subherwal S, Bhatt DL, Li S et al (2012) Polyvascular diseas d long-tern cardiovascular outcomes in older patients with nonST-s amer 'vation myocardial infarction. Circ Cardiovasc Qual Outcome - (4):541-5

26. Preventive Services Task Force US, Curry SJ, Krist , H et al (2018) Scl_ening for peripheral artery disease and cardiovascular sease risk assessment with the ankle-brachial index: US Preventive Services $k$ Force recommendation statement. JAMA. 320(2):177-1

27. Korkmaz L, Adar A, Erkan $\mathrm{H}$ et al (2012) artery lesion complexity in patients with acur. ary syndromes. Angiology. 63(7):495-499

28. Benyakorn T, Kuanprasert S Rern $\mathrm{m} \mathrm{K}$ (2C12) A correlation study between

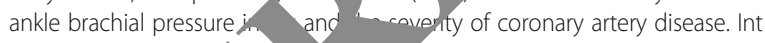
J Low Extrem Woun $11(2),-123$

29. Chen Q, Shi Y, W $>$ Y Y, Li X (2u Datterns of disease distribution of lower extremity perin hero terial disea.e. Angiology. 66(3):211-218

30. Vuruskan E Saracoglu olat M, Duzen IV (2017) Prediction of coronary artery dicease severity in ver extremity artery disease patients: a corre on S udy of TASC II classification, Syntax and Syntax II scores. Cardio J $24(5)$.

31. $\mathrm{A}, \mathrm{M}$, ch H, Qoussoos T et al (2018) Prevalence of previously un cognizeo peripheral arterial disease in patients undergoing coronary . Medicine (Baltimore) 97(29):e11519

\section{Publ),sher's Note}

Springer Nature remains neutral with regard to jurisdictional claims in published maps and institutional affiliations.

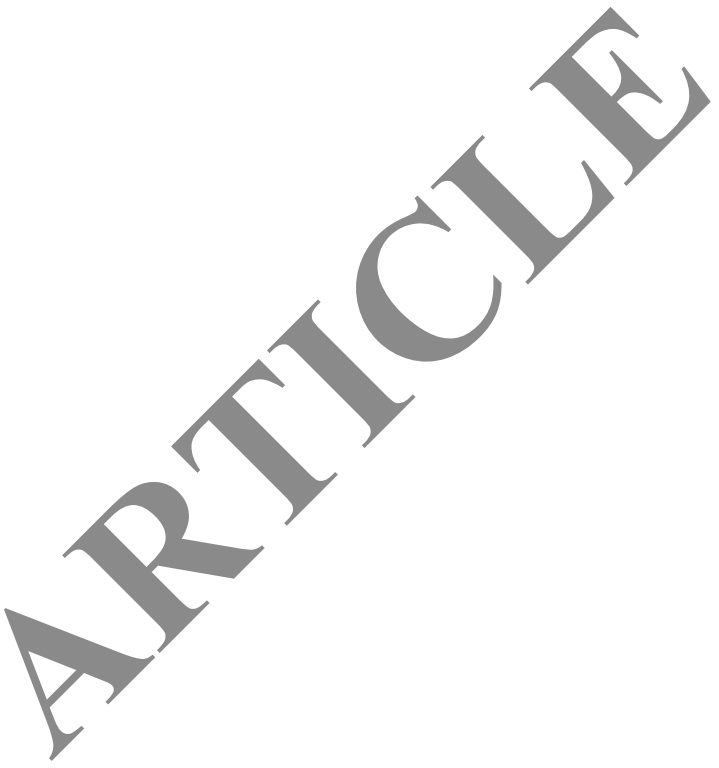

\section{Submit your manuscript to a SpringerOpen ${ }^{\circ}$ journal and benefit from:}

- Convenient online submission

- Rigorous peer review

- Open access: articles freely available online

- High visibility within the field

- Retaining the copyright to your article

Submit your next manuscript at $\boldsymbol{\nabla}$ springeropen.com 